\title{
The Management of Foreigners in the China-Myanmar Border Region
}

\author{
Gu $\mathrm{He}^{1 *}$ \\ School of Public Administration \\ Yunnan University of Finance and Economics \\ Yunnan, P. R. China, 650221 \\ ghguhe@163.com
}

\author{
Yuan Fang ${ }^{2}$ \\ School of Public Administration \\ Yunnan University of Finance and Economics \\ Yunnan, P. R. China, 650221 \\ YF3551@126.com
}

\begin{abstract}
There are several key problems for the management of foreigners in the China Myanmar border area: the dilemmas between border daily life and national regulations, local regulations and national system, lack of multilevel governance mechanism, and so on. It should focus on the characteristics of the border areas, those measures should be done, such as effective management system, and management responsibilities, innovative local governance.
\end{abstract}

Keywords - China-Myanmar border area; The management of foreigners

With globalization, international migration has been increasing. With the development of economy and society, the number of foreigners is increasing in China. It has become one of the foreigners gathered distribution area for China-Myanmar border area. There is $2185 \mathrm{~km}$ for the China-Myanmar border, and it mainly locates in Yunnan Province. Due to the special geographical and social environment, with the rapid development of border trade and tourism, it gathered a large number of foreigners in this area. For example, there are about 50,000 foreigners in a border city, Ruili, and it almost equal the $1 / 4$ of population in this city. In addition, there are from 10,000 to 100,000 illegal immigrants in China Myanmar border, and an unknown number of foreign refugees. Foreigner management has been the most prominent social management problem in this area. Under the special situation of the China-Myanmar border, there are some problems about various policies and regulations, management mechanism and so on.

\section{THE PROBLEM OF FOREIGNERS} MANAGEMENT IN CHINA MYANMAR BORDER AREA

\section{A.The dilemma of the daily life in the border and the national laws}

From the perspective of the state, the management of foreigners is involved in the public policies, and it is related with national laws and regulations. On the other hand, the issue about the management of foreigners also relates with the daily life of residents in the border area, especially cross-border activities and interactions, which also belong to the individual domain. The interweaving of public policies and private lives causes a series of problems.

For a long time, there is a large number of cross-border ethnic groups in the China Myanmar border area, and they have the same or similar culture, close kinship. They has long history for intermarriage, just because of China Myanmar border division makes these groups locate in different countries. There are certain national boundaries for the modern state. The national administrate is restricted by the national boundaries, and the people have their own national identity in the specific national boundaries. Citizens have the rights and obligations under the law of the country. For most of ethnic groups have no definite nationality and law consciousness in the China Myanmar border area for long 
time, even in a period after the conformation of the China-Myanmar border. With the development of state management mechanism, there cross - border activities have been included in the state affairs. Most of the foreigners belongs to the cross-border ethnic groups in the China Myanmar border areas. So there will be such special difficulties for the management of foreigners. Due to the convenience of life and the traditional experience, residents show ignore or disregard the national regulations and policies. The typical example is the cross-border marriage. Over the years, the spouse from international marriage seldom go to government office for registration. Based on public management, it led to a large number of illegal marriage and illegal aliens, also led to problems about the identification of children, education and social security and so on. From the private view, their choices were based on the traditional and daily experiences, which caused the conflicting between their behaviors and national rules.

\section{B.The differing between local policies and national system}

At present, the management of foreigner is mainly based on China immigration control law published on July 1, 2013 , and The Regulations of immigration control published on September 1, 2013.There are also other relevant laws and regulations involved in the management of foreigners in the China-Myanmar border area, such as China Nationality Law, and Regulations for the cross border marriage, and so on.

To the foreigners entering and living in China, according to Article 15, China immigration control law, foreigners shall apply the visa before they enter China. However, in strict accordance with the law, the most of foreigners is illegal in the China-Myanmar border area now. Considering the special status in this area, one policy was published in 1990, Management regulations for migrants and immigrants of Yunnan-Myanmar border areas. Which distinguished from the applicable China immigration control law.

To the employment of foreigners, ,according to Article 41, China immigration control law, foreigners working in China should obtain work permits and work type residence certificates. No unit or individual may employ a foreigner who has not obtained these documents. However, most of residents in the China-Myanmar border area holds the "Yunnan border area entry and exit permit", when they entry into China, then handle the relevant formalities according to local employment requirements. In recent years, due to the rapid development of the China-Myanmar border trade, some measures are implemented in the border cities, such as Dehong in 2014, and Baoshan in 2015.

They facilitated the entry of foreign expatriate residence and employment, but also facilitate the residence and employment of foreign personnel into the management of local governments for these local policies. However, these regulations also caused some problems. In recent years, there are some foreigners who enter into or stay in China illegally or work in China without work permission in the China Myanmar border area, to some extent which shows the conflicts of the local regulations and national policies. Since it is difficult to implement the state regulations in the China-Myanmar border area, local policies are taking approaches. Due to the development of social economy and traffic, it is very easy to migrate from the border areas to the other now. So how to coordinate local regulations and national regulations, which has become a major problem for the department of management of foreigners in the China-Myanmar border area.

\section{Deficiency of multilevel governance mechanisms}

The governance of foreigners' shows multilevel natures. First, the problem of foreigners has dual characteristics: the domestic and international characteristics. The domestic characteristic refers to the influence of the foreigner on the political, economic, cultural and others of the host country, which makes it become the domestic problem of the country. The later refers to the alien issues related to the country of origin, transit and destination country. It is an international problem that crosses national boundaries. As a result, firstly, the governance of foreigners shows the domestic governance of the host country, at the same time, it also involves the international cooperation with original countries and other. Secondly, in the process of domestic governance of foreign, there is a division of responsibilities between the central and local governments: the central government is mainly 
responsible for legislation and law enforcement. The local government can formulate local policies and regulations cooperate with relevant law enforcement work. It is necessary to establish an effective multilevel governance mechanism. That is the multilevel requirements of the governance of the foreign issues.

In domestic governance level, at present, the department of public security is mainly responsible for management of foreigners in China. Public security organs imply the approach-"two institutions, three levels management"-to management of foreigners, extension of the development community to incorporate the range of duties of the police station. However, affairs of foreigner management also belongs to the powers of the central government, especially, foreigners in the China Myanmar border areas also involves complex and sensitive anti-terrorism combat, national security and other issues. Therefore, there territorial administrative way of foreigners also faces a variety of challenges in China Myanmar border region.

In international governance level, the problem of the management of foreigners involves two countries and even multilateral countries or regions, so it is impossible to achieve effective governance if it only relies on one country. At present, it is still complex for Myanmar political situation. For the regions bordering with Yunnan, Kachin State is a autonomy region as the Kachin, Shan State is a state with the largest areas and most populous in Myanmar. There are all kinds ethnic armed forces organization in these two states, although the central government of Myanmar strengthen to clear the armed ethnic forces in recent year, but most of the region is still under the control of the armed ethnic forces. Which leads to unclear citizen identity, the disorder management of the border, also causes refugee immigration and other problems. At present, the international level of the management of foreigners depends on the cooperation of all countries or regions, through the signing of agreements, plans, etc., and take cooperative management. However, to the China Myanmar border area, national control is still weak due to the coexistence of various political forces, so the national cooperation shows the greater limitations and difficulties. In addition, there is also a lack of both sides involved in the
China-Myanmar bilateral agreements related to management of foreigners, which also increases the difficulty of managing foreigners in border areas.

\section{D.The conflict of the management of foreigners and local development}

With the opening and development of China and the developing of China - ASEAN Free Trade Area, it is advantageous to both countries and regions for the cross border migration, especially for the economic and trade development in the China- Myanmar border area. Foreign businessmen are engaged in jewelry jade, cosmetics, clothing, tourism and other work to promote the development of regional trade and services. Some of them understand the two countries' culture and they played an important role in communication between China and neighboring countries and regions. Foreign workers engaged in the construction, catering industry, health massage, transportation and so on, which complements the shortage of local labor, and it benefits the local infrastructure construction and economic development. In addition, the intermarriages between foreigners and domestic residents are beneficial to solve the marriage needs for youths in the border areas. Which also can promote the friendly relations among nations and regions. In other areas of culture and education, foreigners also play a positive role. Currently, foreigners have been widely involved in all aspects of the China-Myanmar border area.

On the other hand, the entry of a large number of foreigners also brought a series of problems, especially for illegal foreigner problems, which linked with the particular geographical environment of the China-Myanmar border region. The Golden Triangle --the one of world drug cultivation and trade main distribution center-- adjacent to Myanmar border area. It has long been plagued by drug abuse problem. At the same time, there are various kinds of transnational crimes and population health problems in the region. In the aspect of social security, foreigners who enter into or stay in China illegally or work in China without work permission are becoming one major factor affecting social security in the China-Myanmar border areas. According to statistics, there are more than 6000 criminal cases in Dehong 
since 2011, arrested more than 4,000 criminals, and foreigners criminals accounted for the $13 \%$ of total number, which is far more than the percentage of the population. For the health of the population, it was found that the Myanmar people account for $24.2 \%$ of more than 20000 cases of AIDS in 1989-2013 years in Dehong. To the cross-border marriage, most of them was not legally registered. Without residence in the territory and identity documents, many spouses have no many rights, such as health, education, social security and so on. And many of these child also have no citizenship.

Foreigners play a positive and constructive role of trade and economic, social, cultural and other in the China-Myanmar border, and social issues associated with foreigners also have an important impact on the social security, population health and other. It has become the important issues to play the role of foreigners in the border areas in economic and social development and deal with foreign-related social issues with foreigners .

\section{SUGGESTIONS OF FOREIGNER MANAGEMENT}

\section{IN THE CHINA-MYANMAR BORDER AREA}

\section{A. Focus on the characteristics of the border areas}

The situation of foreigners in China and Myanmar border areas is different with other areas such as the eastern coastal city, also different with immigration problems in some developed countries. Due to the special geographical environment, social history and culture factor, which cause the particularity of problem of foreigners in the China-Myanmar border region. Such as stateless persons, cross-border marriages, refugee and so on are closely related to the historical changes in the border areas, cross-border ethnic and political situation in northern Myanmar and so on. From the point of view of national level, it needs to focus on the differences of the environment, especially for the particularity of the China-Myanmar border area, and it should introduce corresponding policy support, and give more space to develop local policy. From the local perspective, local governments need to recognize the reality of the region. Foreigners have special relationship with local residents in border areas, such as border trade, cross-border marriages, house rental and so on. So it is impossible to implement the policy if there is no support and understanding of the local residents in border areas. When local authorities implement policy of foreigner management and services, they also need to focus on characteristics of the foreigners in border.

\section{B. Building an effective management system}

The problem of foreigners is related to the management of multiple levels, including transnational governance, national governance and local governance and other. There are many obstacles and difficulties to develop transnational management in the China-Myanmar border area. In order to deal with the problem of foreigners, it should carry out the relevant international cooperation. At present, while promoting economic and trade cooperation with border countries and regions, it also need to promote cooperation in other areas, such as fighting against human trafficking, drug trafficking, disease prevention and control. Also it still need cooperation for international judicial border management, migration control. At the level of national governance, there are formulated policies and regulations related to the management of foreigners in China. Considering of special situation of border areas, under the basis of national regulations and policies, it needs to introduce the opinions of the relevant way to solve the long-standing border region foreigners legacy, such as stateless returned overseas Chinese and their relatives, cross-border marriages spouses and so on; At the level of local governance, it needs to further adapt to the management policy and the reality in the border areas, and the relevant state policies and regulations shape matching, enhance the effectiveness of the relevant policies and measures. The final formation of multilayer system related to the management of foreigners in the China-Myanmar border area, the layers of management system of cooperation, complement each other.

\section{C.Allocating the responsibilities of management}

The foreigner management belongs to the central powers. " The foreigner management embodies the country's jurisdiction, and plays a very important role in promoting national political, economic and cultural exchanges, and safeguard the sovereignty, security and interests of the state, fights against terrorism and violence, and ensure Chinese and 
foreign citizens rights and interests and so on." (Wang Xuelei,2009) At present, China central government authorized public security department at various levels to manage foreigners. On the one hand, although there is no change in the nature of a centrally managed, "but in the objective existence, there are many problems, such as separation of governance and right of management, separation of governance and personal rights, separation of governance and financial power, centralization of state power not concentrated, multi management not unified."(Weng Li, Bi Wei, 2006)

In the current situation, with the separation between foreigner management authority and administrative power, it needs that the state increase the support to the border areas, especially to the less developed areas in border, and increase manpower and material resource, and strengthen grass-roots management service ability. Meanwhile, it should coordinate and deal with the work of different areas in foreigners' management, and share information and data. In view of the future situation of the development of foreign management and services, it should try to reform the management system for foreigners, and solve the problem by the separation of powers and management power of foreigners.

\section{Innovating the local governance}

The foreign management involves the national laws and regulations. However, due to the great differences among the regions, for the policies of management of foreigners, it need to be based on local design. At present, there are some new measures for the management of foreign in some of the eastern coastal provinces of China, such as Guangdong Province, the first one to develop specialized regulations for the management of foreigners. It promulgated the "Provisional Regulations on the management and services of foreign in Guangdong province" in 2011. It can be learned for these experiences to the China-Myanmar border area. On the other hand, with the development of society and economy, the deepening of regional cooperation, it become more and more important role for the China-Myanmar cross-border areas. For example, Ruili city was named as the national open test area in June 2010. In recent years, under the support of relevant national policies, there are many innovating policies for the management and services of foreign in Ruili. At present, the further opening of the border and the active support from the state provides a broad space for the development of management services innovation in the border areas. It needs to innovate management services for foreigners working mechanism and multi-sectoral collaboration management service mechanism, and absorb social organizations, business department and community members participate in the foreigner service and innovation related information collection mechanism analysis.

\section{ACKNOWLEDGMENT}

Colleges and Universities Cooperation Projects in Yunnan Province in 2013: The Research on the problems of "Three Non-" Aliens in China-Myanmar Border Region.

\section{REFERENCES}

[1] The Exit and Entry Administration Law of the People's Republic of China. 2013-7-1

[2] Anthony Giddens. Nation State and Violence [M].Triple Bookstore.1998:60

[3] Chen Jimin. Research of The Illegal Immigrants Governance in the Era of Globalization [D]. Foreign Affairs College. 2011-8

[4] Wang Xuelei. Thinking of Improve Our Country's Entry and Exi Management System [J]. Law and Society, 2009(9)

[5] Weng Li, Bi Wei. Choice of China Entry-Exit Management System [J]. Journal of Zhejiang University (Humanities and Social Sciences Edition ). 2006(4)

[6] Management regulations of Yunnan-Burma border areas outside people entry and exit. 1990

[7] Interim Measures for the administration of overseas immigration personnel in Ruili 